\title{
Critical Rainfall Analysis on Flash Flood Early Warning for South Branch of Censhui Watershed
}

Changzhi Li ${ }^{1,2}$, Hong Wang ${ }^{1}$, Xiaotao Cheng ${ }^{1,2}$, Baozhao Yuan ${ }^{3}$, Meihong Ma ${ }^{4}$, Changjun Liu ${ }^{1,2}$, and Dongya Sun ${ }^{1,2}$

1. China Institute of Water Resources and Hydropower Research, Beijing 100038, China

2. Center of Flood and Drought Disaster Reduction of Ministry of Water Resources, Beijing 100038, China

3. Jingshui River (Beijing) Water Engineering Consulting Company Limited, Beijing 100038, China

4. Beijing Normal University, Beijing 100038, China

\begin{abstract}
Critical rainfall for flash flood early warning is a converse result of precipitation-runoff process based on warning discharge threshold for a warning station of interest in a watershed; the key aspects of critical rainfall include rainfall amount and rainfall duration. Using hydrological modeling technique with detailed sub-basin delineation and manual for design precipitation-runoff computation, this study introduces basic concept and methods of analyzing critical rainfall for flash flood early warning. Taking South Branch of Censhui watershed in China as an example, typical critical rainfalls for flash flood dynamic early warning were estimated for 3 warning stations located in the watershed. This research illustrates that detailed watershed characteristics in the context of several warning stations can be modeled in-depth by further delineating the watershed into smaller sub-basins to simulate spatial distribution of various basin parameters. It further confirms that time of concentration of a watershed is an important factor to rainfall duration determination, and the antecedent soil moisture condition of a watershed has significant impact on critical rainfall for same rainfall duration.
\end{abstract}

Key words: Small watershed, flash flood early warning, critical rainfall.

\section{Introduction}

As global climate changing and extreme weather events increasing, flash flood disasters are rising and drawing substantial attention around the world. Flash flood can be characterized as sudden occurrence, wide impact and, destructive damage. The forecasting and early warning of flash flood is full of challenges because of its complexity. Consequently, flash flood early warning becomes one of the key issues for lives and properties protection in mountainous or hilly areas. Flash flood early warning is often conducted using critical rainfall as a warning indicator. Critical rainfall is an estimate of the amount of rainfall required over a given area during a given duration to cause a mountain stream to flood at a given warning station. Although critical rainfall method has been widely used in the

Corresponding author: Changzhi Li, Ph.D., senior engineer, research field: flood defense. flash flood early warning, the determination of critical rainfall varies significantly. The FFG (flash flood guidance system) developed by the United States is commonly used as an early warning system $[1,2]$. FFG method and related early warning systems are also used in many other countries and regions around globe [3-6]. At present, this system is being continuously improved and refined $[2,7]$. In recent years, more detailed data and refined methods were used to explore flash flood early warning [8], especially for regions without streamflow records [9]. Critical rainfall analyses are more focused on precipitation and soil moisture content and for debris flow and landslide warning in Japan, and commonly used methods include soil moisture index, effective precipitation, rainfall intensity/time of concentration, and statistics based multi-determination analysis [10]. JAN provided a method for critical rainfall analysis which mainly focuses on rainfall intensity and accumulative 
rainfallfor predicting possibility debris flow patterns and early warning $[11,12]$. In mainland China, climate conditions, geological landforms, vegetation and soil types vary vastly; similarly, there are significant variations in availability of historical precipitation and streamflow data in different regions. As a result, various experimental or too complicatedmethods are used for critical rainfall analysis, such as statistical analysis of measured rainfall data [13], warning stage/warning discharge calculation [14], rainstorm critical curve method [15], and hydrodynamic method [16].

China has mountainous and hilly areas around $2 / 3$ of land that are flash-flood-prone area. In recent years, great efforts have been paid in Chinato increase capacity of flash flood prevention. It is difficult in China at present to practice FFGmethod for poor availability of continuous precipitation information in many areas while preliminary research indicates that FFG method will perform very well on the base of available continuous and dynamic precipitation information. However, China's most provinces have their practicalmanuals for local precipitation-runoff analysis. In these manual, the methodologies and parameters are introduced in detail for design rainstorm computation, flood runoff analysis, and their engineering application.

Using hydrological modeling and "Manual for Rainstorm-Runoff Analysis in Hunan Province" [17], this paper attempts to establish a methodto critical rainfall analysis for flash flood early warning. To demonstrate the approach, the South Branch of Censhui watershed in Hunan province was taken as an example and the results show that the proposed method is practical and applicable, and can provide critical rainfall information for flash flood dynamic early warning.

\section{Research Concept and Approach}

Critical rainfall for flash flood early warning is a converse result of rainstorm-runoff process based on warning discharge threshed for a warning station of interest in a watershed; rainfall amount and rainfall duration are the key aspects of critical rainfall. The basic concept and approach in this study are as follow: using detailed hydrological modeling to simulate flood hydrographs at various early warning stations inside a watershed; determining the lag time based on the peak-precipitation time and peak-flood time, using the lag time to backtrack critical rainfall value at each early warning stations, as shown in Fig. 1. During the development of the detailed hydrological model, special attention was paid to the followings: (1) in the

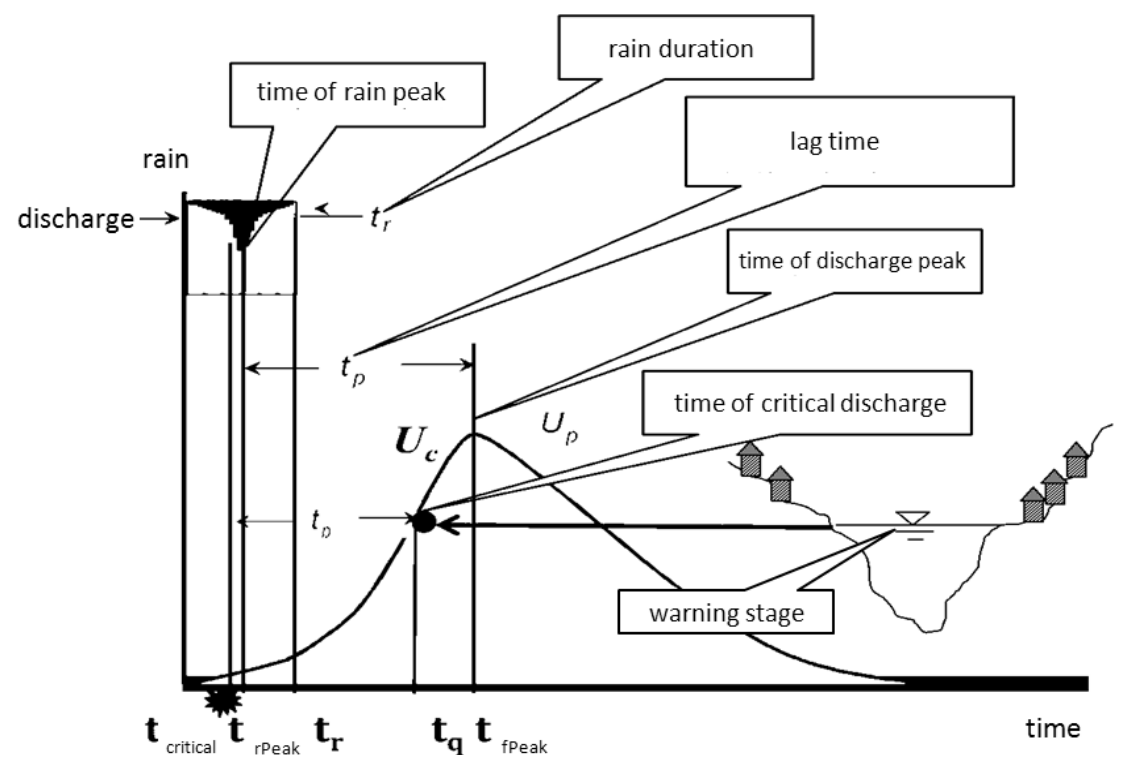

Fig. 1 Schematics for estimating warning indicators. 
process of sub-basin delineation, the geographical locations of the early-warning stations were appropriately considered as well as the river sections, source and sink points, tributary confluences and diversions; (2) carefully collecting and inputting parameters for each sub-basin such as topographical features, vegetation covers, land uses types, soil types, and river features; (3) utilizing historical and typical precipitation and streamflow data in the watershed to calibrate and validate the model.

On the base of the development of the detailed hydrological model, the analysis was performed according to the following steps: step1, determining rainfall duration according to analysis on time of concentration of a watershed; step 2, estimating the warning discharge threshold for each warning station based on its warning stage using discharge and water stage transformation, for instance, Manning's formula; step 3, assuming typical soil moisture conditions for runoff volume analysis; step 4, selecting rainfall pattern for precipitation series input, for during hydrological analysis, a hypothetical precipitation series was constructed by assuming an initial total rainfall value and distributing the total rainfall amount to each time step based on the rainfall pattern; step 5, critical rainfall computation and analysis was conducted by error and trial procedure, this hypothetical precipitation series in step 4 was input into the model, and the resulted flood hydrograph at each early-warning station was compared with pre-determined warning discharge; if computed peak flow differs from warning discharge significantly, the initial total rainfall amount will be adjusted, and the simulation repeats, until the simulated peak flow at each early warning station matches pre-determined warning discharge within pre-defined tolerance.

\section{Critical Rainfall Computation}

\subsection{Description of Study Area}

Located in Hunan Province

$\left(113^{\circ} 13^{\prime} 25.3^{\prime \prime}-113^{\circ} 29^{\prime} 14.8^{\prime \prime}\right.$ E, 2943'29.01"-2951'27"
N) with an drainage area of $223 \mathrm{~km}^{2}$ and longest flow way of $33.6 \mathrm{~km}$, South Branch of Censhui watershed is a wet subtropical monsoon climate region with an annual precipitation of 1,200 1,900 mm. Rainfall concentrates in summers, and heavy storms often trigger flash flood in this area in summer. The watershed is bordered by mountains at west, south and north, and the elevations descent from west to east. The South Branch of Censhui Creek originates from Yanzi Village, Shimen County. It flows in the valley eastwards through 5 towns and enters into Wangjiachang Reservoir. The creek consists of 3 main tributaries. The tributary 1 is located at the most upstream. It flows mainly through Shimen County. The watershed is predominately wooded mountainous area covered with light to dense trees and grass. The flash flood early-warning stations are marked as A, B and C. Station A is located near the mouth of the main creek, the backwater area of Wanjiachang Reservoir; the recipient of the warning is anenterprise; station $\mathrm{B}$ is located at the confluence of the tributary 2 and the main creek, its recipient is a town crossing the main creek by a bridge; station $\mathrm{C}$ is located at the confluence of the tributary 1 and the main creek, its recipient is a confluence. There was a hydrologic station, Lianhuayuan Station, located between warning station B and warning station A on the main creek (refer to Fig. 2) which was removed after the construction of Wangjiachang Reservoir. Moreover, there was a rain gauge station, Liangshuijing Station, in the upper reach of the main creek (refer to Fig. 2).

In the past, this watershed has been frequently attacked by flash flood. Major flood damagesoccurred during the storm events of 1909, 1935, 1954, 1963, 1966, 1980, 1983, 1998 and 2003. The historical streamflow data of the Lianhuayan Station indicate that during 1909's flash flood event, the recorded peak discharge and river stage reached $1,980 \mathrm{~m}^{3} / \mathrm{s}$ and 94.32 m, respectively; during 1935's event, the peak discharge and river stage reached $1,290 \mathrm{~m}^{3} / \mathrm{s}$, and 93.35 m, respectively; during 1966's event, the peak discharge 


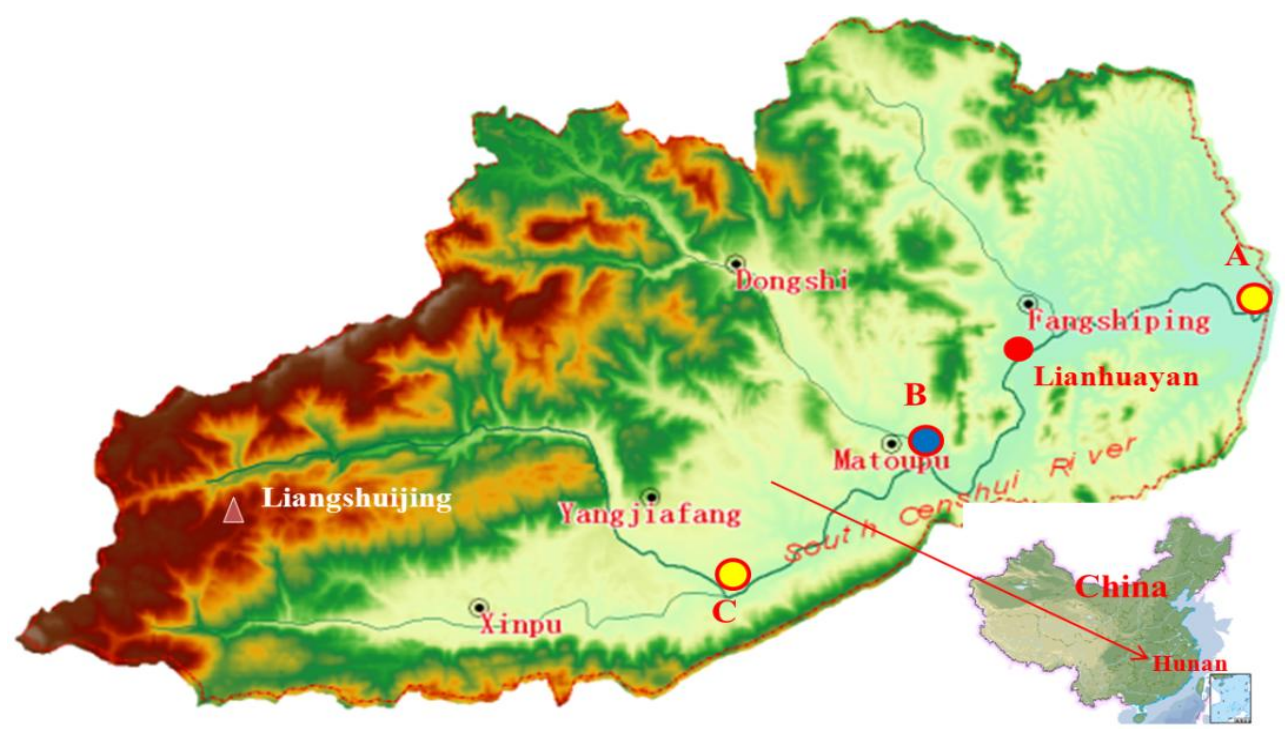

Fig. 2 Sketch of South Branch of Censhui Watershed.

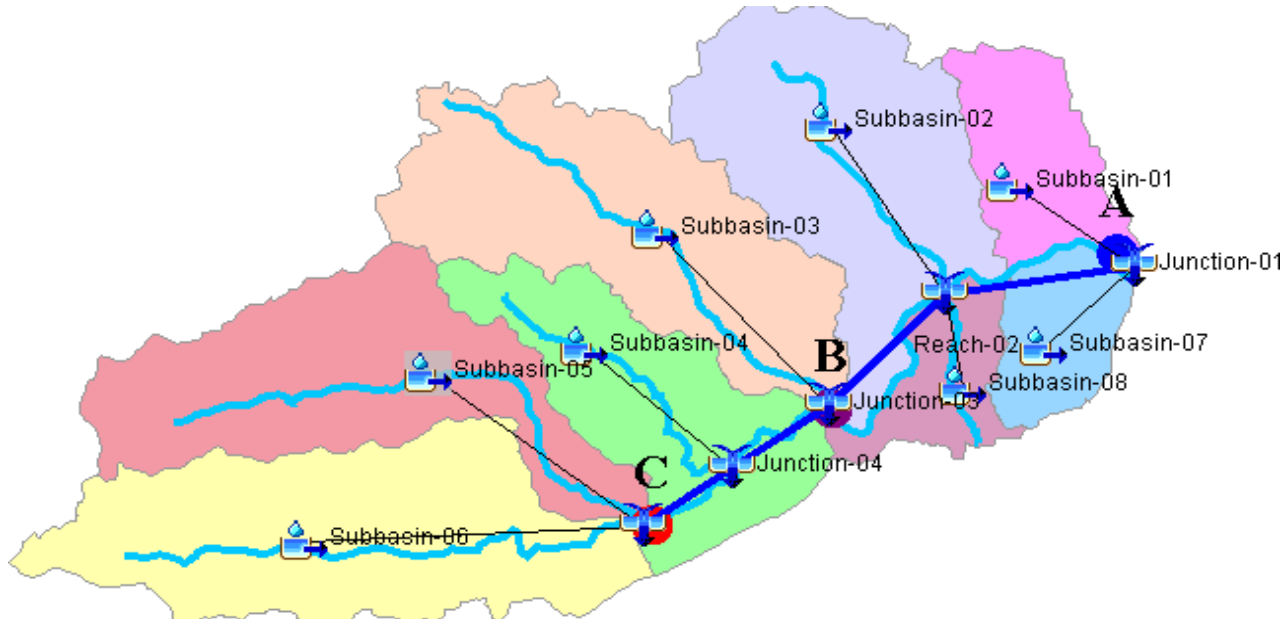

Fig. 3 Watershed delineation and early warning stations.

and river stage reached $667 \mathrm{~m}^{3} / \mathrm{s}$ and $93.11 \mathrm{~m}$, respectively.

\subsection{Model Development and Calibration}

\subsubsection{Model Development}

The computer program HEC-HMS developed by US Army Corps of Engineers (USACE) was used to conduct this research for its flexibility and commonality for rainstorm-runoff process simulation. According to the river networks and its 3 specific spatial location of the early-warning objects, the watershed is divided into 8 sub-basins, 4 river reaches, and 5 junction points in this study. The sketch of the model basics and early-warning objects are illustrated in Fig. 3.

The SCS Curve Number (SCS CN) method was used to compute the loss before the start of surface runoff; the SCS Unit Hydrograph (SCS UH) transform method was used to estimate surface runoff; and the exponential recession model was used to calculate watershed base flow. The major characteristics for each sub-basin are listed in Table 1.

The flood flow was routed through river reaches with the kinematic-wave method for the considerable slope of channel. Table 2 presents the detailed and key information for each river reach, including creek name, creek length, slope of channel, shape of cross section, and side-slope. 
Table 1 Major characteristic for Censhui Watershed sub-basins.

\begin{tabular}{|c|c|c|c|c|c|c|c|c|c|}
\hline No. & Sub-basin & $\begin{array}{l}\text { Area } \\
\left(\mathrm{km}^{2}\right)\end{array}$ & $\begin{array}{l}\text { Initial } \\
\mathrm{CN}\end{array}$ & $\begin{array}{l}\text { Calibrated } \\
\mathrm{CN}\end{array}$ & $\begin{array}{l}\text { Impervious } \\
\text { Area }(\%)\end{array}$ & Land cover & $\begin{array}{l}\text { Total } \\
\text { volume }\end{array}$ & $\begin{array}{l}\text { Direct } \\
\text { runoff }\end{array}$ & Base flow \\
\hline 1 & sub-1 & 13.90 & 75 & I & 9 & Wood/grassland & \multirow{8}{*}{ SCS CN } & \multirow{8}{*}{ SCS UH } & \multirow{8}{*}{ Recession } \\
\hline 2 & Sub-2 & 38.37 & 75 & I & 8 & Wood/grassland & & & \\
\hline 3 & Sub-3 & 40.84 & 75 & 71 & 10 & Wood/grassland & & & \\
\hline 4 & Sub-4 & 27.80 & 82 & 77 & 8 & Wood/grassland & & & \\
\hline 5 & Sub-5 & 38.38 & 75 & 71 & 8 & Wood/grassland & & & \\
\hline 6 & Sub-6 & 44.75 & 75 & 71 & 6 & Wood/grassland & & & \\
\hline 7 & Sub-7 & 9.74 & 75 & / & 6 & Wood/grassland & & & \\
\hline 8 & Sub-8 & 9.59 & 75 & I & 5 & Wood/grassland & & & \\
\hline
\end{tabular}

(The sign "/" in the column "Calibrated CN" means the non-calibrated CN value due to the downstream of Lianhuayan Station.)

Table 2 Major characteristics for each river reach.

\begin{tabular}{llllllll}
\hline No. & River reach & Length $(\mathrm{m})$ & $\begin{array}{l}\text { Channel slope } \\
(\%)\end{array}$ & Shape of cross-section & $\begin{array}{l}\text { Width of } \\
\text { cross-section }(\mathrm{m})\end{array}$ & $\begin{array}{l}\text { Side-slope } \\
(\mathrm{H}: \mathrm{V})\end{array}$ & $\begin{array}{l}\text { Routing } \\
\text { method }\end{array}$ \\
\hline 1 & R-1 & 2,734 & 4.0 & & 50.0 & 1.9 & \\
2 & R-2 & 3,216 & 1.6 & Trapezoidal & 38.0 & 1.0 & Kinematic \\
3 & R-3 & 5,626 & 5.0 & 50.0 & 1.3 & wave \\
4 & R-4 & 5,536 & 4.9 & 80.0 & 1.1 & \\
\hline
\end{tabular}

\subsubsection{Model Calibration}

All parameters used in the hydrological analyses at the very beginning were set according to the reference manual of HEC-HMS software, so as the specified conditions concerning the analyses in the watershed. Then the model calibration for reasonable values of key parameter $(\mathrm{CN})$ for each sub-basin was performed using the historical streamflow data at Lianhuayan hydrological station, and the corresponding historical rainfall data at Liangshuijing rain gauge station, during June 26-27, 1966 flood event. In fact, the available historical rainstorm-runoff data are badly lacking in this watershed and that in 1966 flood event is the only rainstorm-streamflow matching one available. The objective function provided by HEC-HMS computer software includes sum of absolute errors, sum of squared residuals, percent error in peak, and peak-weighted root mean square error, which were used to find reasonable parameters that yield the minimum value of the objective function. In this study, the best one is the function of sum of absolute errors. Table 1 presents the reasonable calibrated $\mathrm{CN}$ value (5th column) while Fig. 4 demonstrates the comparison between the computed and field measured flood hydrograph at Lianhuayan hydrological station. As illustrated in Fig. 4, both computed temporal and numeric results of the peak discharge were well agreed with the measured data, which indicates the model was reliable for further analyses.

\section{Critical Rainfall Analysis}

\subsection{Warning Rainfall Duration Determination}

Durations of critical rainfall are related to various factors, for instance, catchment area and shape, rainfall intensity, topography, vegetation, soil type, etc. The rainstorm-runoff processes for small basins are largely depended on basin topography and water course characteristics, and the time of concentration of thebasin has a significant impact on basin warning rainfall duration. Time of concentration can also be used as the longest warning rainfall duration for early warning. In addition, a series of shorter leading times should also be considered based on factors such as rainstorm characteristics, basin area, basin slope, shape factors, surface conditions, etc.

Using rainfall intensity described in "Manual for Rainstorm-Runoff Analysis in Hunan Province" and rational method, the time of concentration for the watershed is generally estimated to be about 5 hours. 


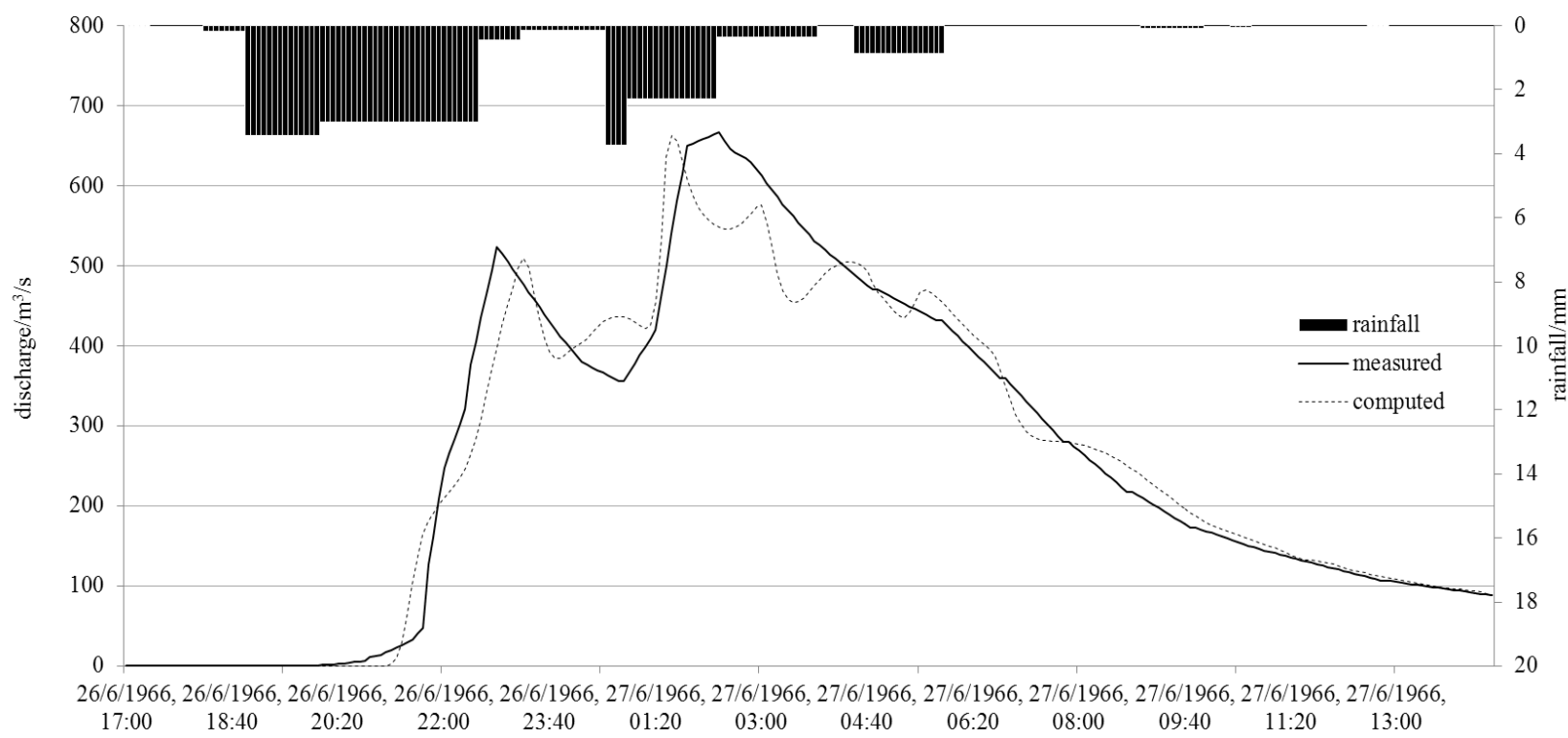

Fig. 4 Comparison between the computed and measured flood process at Lianhuayan hydrological station, on June 26-27, 1966.

Table 3 The results and values of parameters for time of concentration.

\begin{tabular}{llllllll}
\hline $\mathrm{L} / \mathrm{km}$ & $\mathrm{J} / \% \mathbf{0}$ & $\mathrm{m}$ & $\mathrm{Q}_{\mathrm{m}} / \mathrm{m}^{3} / \mathrm{s}$ & $\alpha$ & $\beta$ & $\tau / \mathrm{hr}$ \\
\hline 33.6 & 7 & 1.6 & 1,347 & $1 / 3$ & $1 / 4$ & 5.05 & \\
\hline
\end{tabular}

The rational method for estimating time of concentration is as follow:

According to Ref. [18], mean concentration velocity at basin level $\left(v_{\tau}\right)$ is used to reflect the characteristics of slope concentration and channel concentration:

$$
v_{\tau}=m J^{\alpha} Q_{m}^{\beta}
$$

That provide the time of concentration of basin as

$$
\tau=0.278 \frac{L}{V_{\tau}}=0.278 \frac{L}{m J^{\alpha} Q_{m}^{\beta}}
$$

where, $\tau$ : time of concentration, hr; L: the longest distance from the river mouth to the divide of basin, $\mathrm{km}$; $\mathrm{J}$ : the mean slope of $\mathrm{L} ; m$ : experimental parameter for concentration; $Q_{m}$ : peak discharge, $\mathrm{m}^{3} / \mathrm{s} ; \alpha, \beta$ : experimental exponent, $1 / 3$ and $1 / 4$ for triangular cross section in mountainous and hilly area.

Table 3 presents the results and values of parameters for time of concentration that is over 5 hours. Hence, the time of concentration of the watershed was determined as 6 hours in this study. However, warning rainfall duration of 12 hours was added for the sake of operation and safety, and the rainfall duration of 1 hour,
3 hours, 6 hours, and 12 hours were chosen as warning rainfall duration for critical rainfall analysis.

\subsection{Warning Discharge Threshold Calculation}

The threshold discharges for early warning at 3 early warning stations $(\mathrm{A}, \mathrm{B}, \mathrm{C})$ were determined based on the threshold river stage and the river cross section at each location. Manning's Formula was used to convert threshold river stage to threshold discharge. The results are listed in Table 4.

\subsection{Soil Moisture Content Consideration}

Soil moisture content has a significant impact on watershed runoff, and consequently, will affect the critical rainfall for each warning station. Due to serious shortage of data on soil moisture content, 3 scenarios were considered to simplify and simulate soil moisture content for the entire watershed in this study: (1) dry antecedent soil moisture, simulating drought preceding condition; (2) normal antecedent soil moisture, simulating normal preceding condition; and (3) wet 
Table 4 Summary of threshold discharge at each early warning station.

\begin{tabular}{lllllll}
\hline $\begin{array}{l}\text { Warning } \\
\text { station }\end{array}$ & $\begin{array}{l}\text { River slope } \\
/ \% \text { o }\end{array}$ & $\begin{array}{l}\text { Manning's coefficients } \\
n\end{array}$ & $\begin{array}{l}\text { Ave. velocity } \\
/ \mathrm{m} / \mathrm{s}\end{array}$ & $\begin{array}{l}\text { Cross section area } \\
/ \mathrm{m}^{2}\end{array}$ & $\begin{array}{l}\text { Threshold discharge } \\
/ \mathrm{m}^{3} / \mathrm{s}\end{array}$ & Local name \\
\hline A & 0.86 & 0.035 & 2.87 & 470 & 1,347 & Long Pond \\
B & 2.5 & 0.035 & 2.90 & 81.4 & 670 & Matoupu Town \\
C & 4.5 & 0.045 & 4.12 & 120 & 494 & Yangma border \\
\hline
\end{tabular}

Table 5 Rainfall patterns used in critical rainfall analysis.

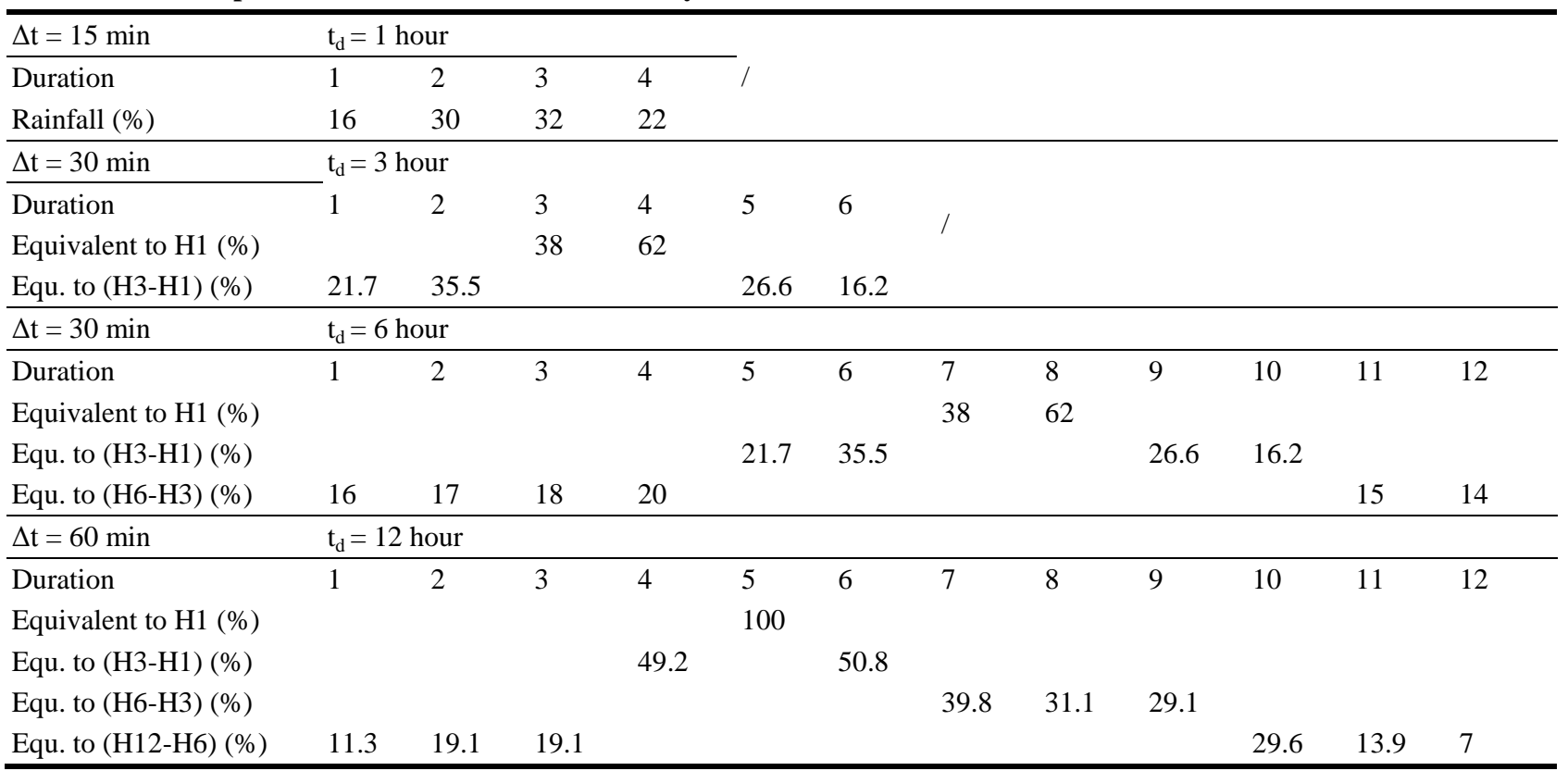

( $t_{d}$ is total rainfall duration, $\Delta \mathrm{t}$ is rainfall time step, $\mathrm{H} 1$ is 1 hour rainfall depth, and so on.)

antecedent soil moisture, simulating wet preceding condition. Watershed maximum storage capacity $\left(\mathrm{W}_{\mathrm{m}}\right)$ of $100 \mathrm{~mm}$ was obtained from "Manual for Rainstorm-Runoff Analysis in Hunan Province". Based on the maximum storage capacity of the watershed, the watershed storage capacities are set as $50 \mathrm{~mm}$ for scenario $1,75 \mathrm{~mm}$ for scenario 2 , and $90 \mathrm{~mm}$ for scenario 3. Consequently, the initial lossesfor 3 scenarios are $50 \mathrm{~mm}, 25 \mathrm{~mm}$, and $10 \mathrm{~mm}$, respectively.

\subsection{Rainfall Pattern and Intensity Analysis}

As described in Section 2 of this paper, the 24-hour precipitation series was constructed by assuming an initial total rainfall value and distributing the total rainfall value to each time step based on the rainfall pattern. The warning periods of 1-hour, 3-hours, 6-hours, and 12-hours were converted from 24-hour rainfall, that is, the critical rainfall analysis requires the distribution of 1-hour storm, 3-hours storm, 6-hours storm, and 12-hours storm as input to match the warning discharge thresholds for each warning station. The rainfall pattern used in this study is summarized in Table 5 according to "Manual for Rainstorm-Runoff Analysis in Hunan Province".

In "Manual for Rainstorm-Runoff Analysis in Hunan Province", the mean 24-hour precipitation $\left(H_{24}\right)$ can be found out in its isopluvial maps, and converted into rainfall depth of various duration as follow.

$$
\left\{\begin{array}{l}
H_{t}=H_{24} \cdot 24^{n_{3}-1} \cdot 6^{n_{2}-n_{3}} \cdot t^{1-n_{2}} \quad 1 h_{r} \leq t \leq 6 h_{r} \\
H_{t}=H_{24} \cdot 24^{n_{3}-1} \cdot t^{1-n_{3}} \quad 6 h_{r}<t \leq 24 h_{r}
\end{array}\right.
$$

in which, $H_{t}$ : rainfall depth of t-hour duration, $\mathrm{mm}$; $n_{2}, n_{3}$ : attenuation coefficients for rainstorm duration of 1 6 hours and 6 24 hours, respectively.

\subsection{Results}

Using hydrological model, the critical rainfall depths 
at 3 warning stations ( $\mathrm{A}, \mathrm{B}$, and $\mathrm{C}$ ) were simulated for above described 3 scenarios. The results are presented in Table 6. The results are summarized as follows:

(1) For drought condition (scenario 1), the depths of 1-hour critical rainfall at station $\mathrm{A}, \mathrm{B}$, and $\mathrm{C}$ are 111 $\mathrm{mm}, 89 \mathrm{~mm}$, and $100 \mathrm{~mm}$, respectively; that of 3-hour critical rainfall are $140 \mathrm{~mm}, 112 \mathrm{~mm}$, and $126 \mathrm{~mm}$, respectively; that of 6-hour critical rainfall are $151 \mathrm{~mm}$, $123 \mathrm{~mm}, 140 \mathrm{~mm}$, respectively; and that of 12-hour critical rainfall are $201 \mathrm{~mm}, 167 \mathrm{~mm}, 191 \mathrm{~mm}$, respectively.

(2) For normal condition (scenario 2), the depths of 1-hour critical rainfall at station $\mathrm{A}, \mathrm{B}$, and $\mathrm{C}$ are $89 \mathrm{~mm}$, $69 \mathrm{~mm}$, and $80 \mathrm{~mm}$, respectively; that of 3-hour critical rainfall are $116 \mathrm{~mm}, 90 \mathrm{~mm}$, and $105 \mathrm{~mm}$, respectively; that of 6-hour critical rainfall are $128 \mathrm{~mm}, 100 \mathrm{~mm}$, $115 \mathrm{~mm}$, respectively; and that of 12-hour critical rainfalls are $170 \mathrm{~mm}, 135 \mathrm{~mm}, 156 \mathrm{~mm}$, respectively.

(3) For wet condition (scenario 3), the depths of 1-hour critical rainfall at station $\mathrm{A}, \mathrm{B}$, and $\mathrm{C}$ are $77 \mathrm{~mm}$, $57 \mathrm{~mm}$, and $68 \mathrm{~mm}$, respectively; that of 3-hour critical rainfall are $102 \mathrm{~mm}, 77 \mathrm{~mm}$, and $90 \mathrm{~mm}$, respectively; that of 6-hour critical rainfall are $116 \mathrm{~mm}, 88 \mathrm{~mm}, 102$ $\mathrm{mm}$, respectively; and that of 12-hour critical rainfall are $153 \mathrm{~mm}, 118 \mathrm{~mm}, 139 \mathrm{~mm}$, respectively.

Table 6 demonstrates the following trends:

(1) For all 3 scenarios, critical rainfall depth increases as warning duration increases. (2) Antecedent soil condition impacts critical rainfall depth significantly. Fig. 5 depicts the differences of critical rainfall depth under 3 scenarios. The first graph plots the difference of critical rainfall depth between normal and wet condition; it shows a difference of 10 $\mathrm{mm}$ for rainfall durations not exceed 6 hours. The second graph depicts the difference of critical rainfall depth between drought and normal condition; it indicates a difference of $20 \mathrm{~mm}$ for rainfall durations not exceed 6 hours. The third graph is the difference of critical rainfall depth between drought and wet condition; it demonstrates a difference of $30 \mathrm{~mm}$ for rainfall durations not exceed 6 hours. For rainfall duration of 12-hour, all 3 graphs show a larger difference than shorter rainfall durations. It is concluded that the antecedent soil moisture condition plays an important role in the forecasting of flash flood; and therefore, special attention should be given to it in the early warning determination.

\section{Results Application}

As accurate as the tabular format is, it is not most preferred format to real-world application. Graphical format, on the contrary, is more visual and user-friendly. Therefore, the results were plotted in Fig. 6. According to a previous research for this region [17], $80 \%$ of time the antecedent soil moisture conditionbelongs to the normal condition. Therefore, the Scenario 2-normal condition results should be used for many cases; the results from other 2 scenarios should be considered as references when reaching final warning decisions.

Table 6 Summary of critical rainfalls at each early warning station.

\begin{tabular}{|c|c|c|c|c|c|c|c|c|c|c|}
\hline \multirow{3}{*}{\multicolumn{2}{|c|}{$\begin{array}{l}\text { Location/station } \\
\text { Warning discharge }\left(\mathrm{m}^{3} / \mathrm{s}\right) \\
\text { Soil moisture content }\end{array}$}} & \multicolumn{3}{|c|}{ A } & \multicolumn{3}{|c|}{ B } & \multicolumn{3}{|c|}{$\mathrm{C}$} \\
\hline & & \multicolumn{3}{|c|}{1,347} & \multicolumn{3}{|c|}{670} & \multicolumn{3}{|c|}{494} \\
\hline & & $\mathrm{Mc}$ & $\mathrm{Md}$ & $\mathrm{Mw}$ & $\mathrm{Mc}$ & $\mathrm{Md}$ & $\mathrm{Mw}$ & $\mathrm{Mc}$ & $\mathrm{Md}$ & $\mathrm{Mw}$ \\
\hline \multirow{4}{*}{$\begin{array}{l}\text { Critical } \\
\text { rainfall } \\
(\mathrm{mm})\end{array}$} & $1 \mathrm{~h}$ & 89 & 111 & 77 & 69 & 89 & 57 & 80 & 100 & 68 \\
\hline & $3 \mathrm{~h}$ & 116 & 140 & 102 & 90 & 112 & 77 & 105 & 126 & 90 \\
\hline & $6 \mathrm{~h}$ & 128 & 151 & 116 & 100 & 123 & 88 & 115 & 140 & 102 \\
\hline & $12 \mathrm{~h}$ & 170 & 201 & 153 & 135 & 167 & 118 & 156 & 191 & 139 \\
\hline
\end{tabular}

(* Md, Mc, Mw represent drought, normal, and wet condition, respectively.) 

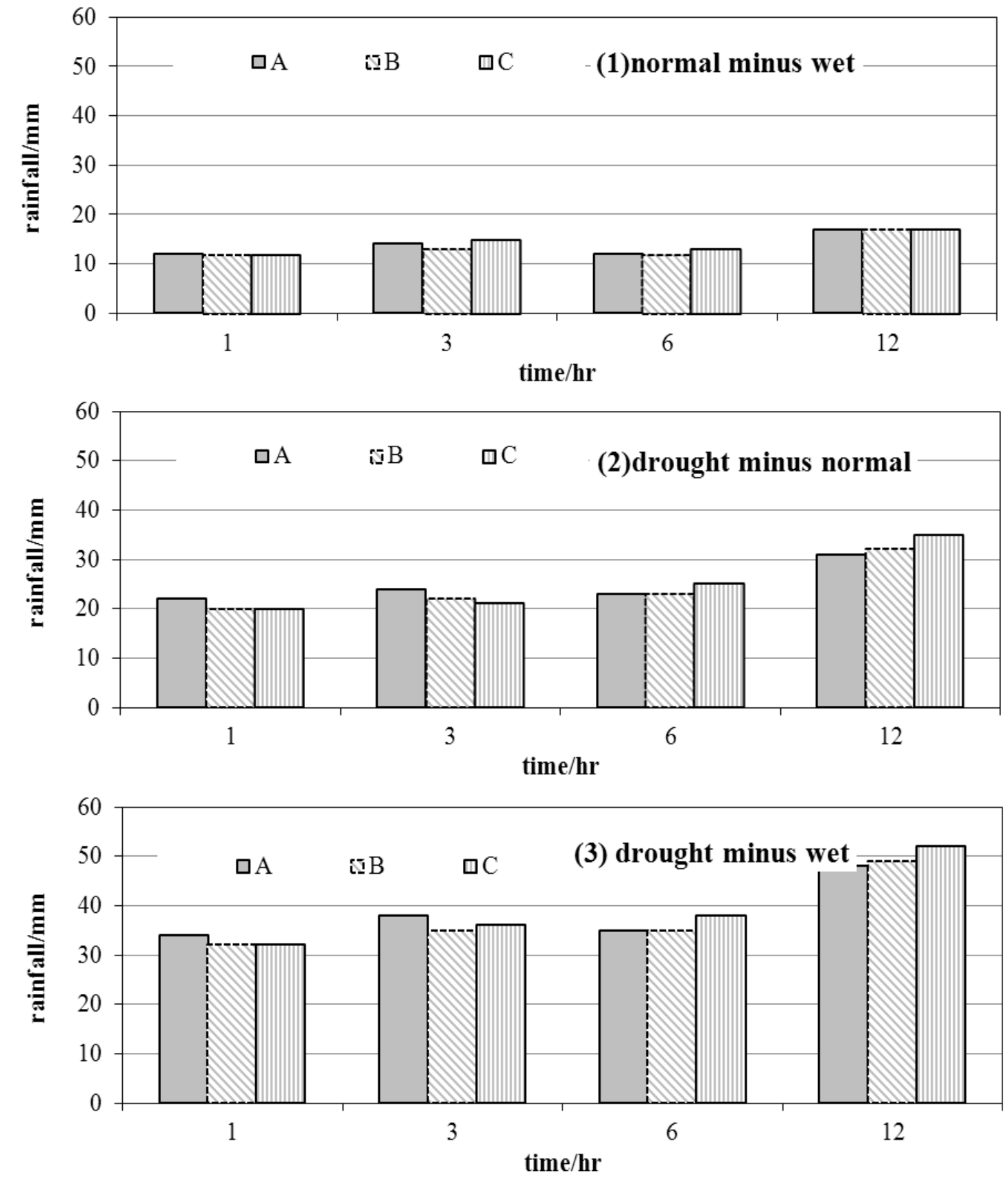

Fig. 5 Critical rainfall difference in 3 scenarios.

The last graph in Fig. 6 is an application schematic. The thick-solid line represents the cumulative rainfall depth; the dashed line represents critical rainfall depth. When the cumulative rainfall curve intersects criticalrainfall curve, a warning should be issued. From this graph, if the cumulative rainfall depth does not exceedcritical rainfall depth, when a rainstorm event (as $1 \mathrm{~h}$, and $3 \mathrm{~h}$, and $6 \mathrm{~h}$, and $12 \mathrm{~h}$ ) is predicted, the cumulated rainfall depth can be predicted as well, and the results will show whether or not the cumulative rainfall curve will exceed critical rainfallcurve, and in turn, an early warning decision can be made. In order to achieve dynamic rainfall alert, this information should be updated at regular intervals, such as 3 hours, 1 hour, even 30 minutes. 

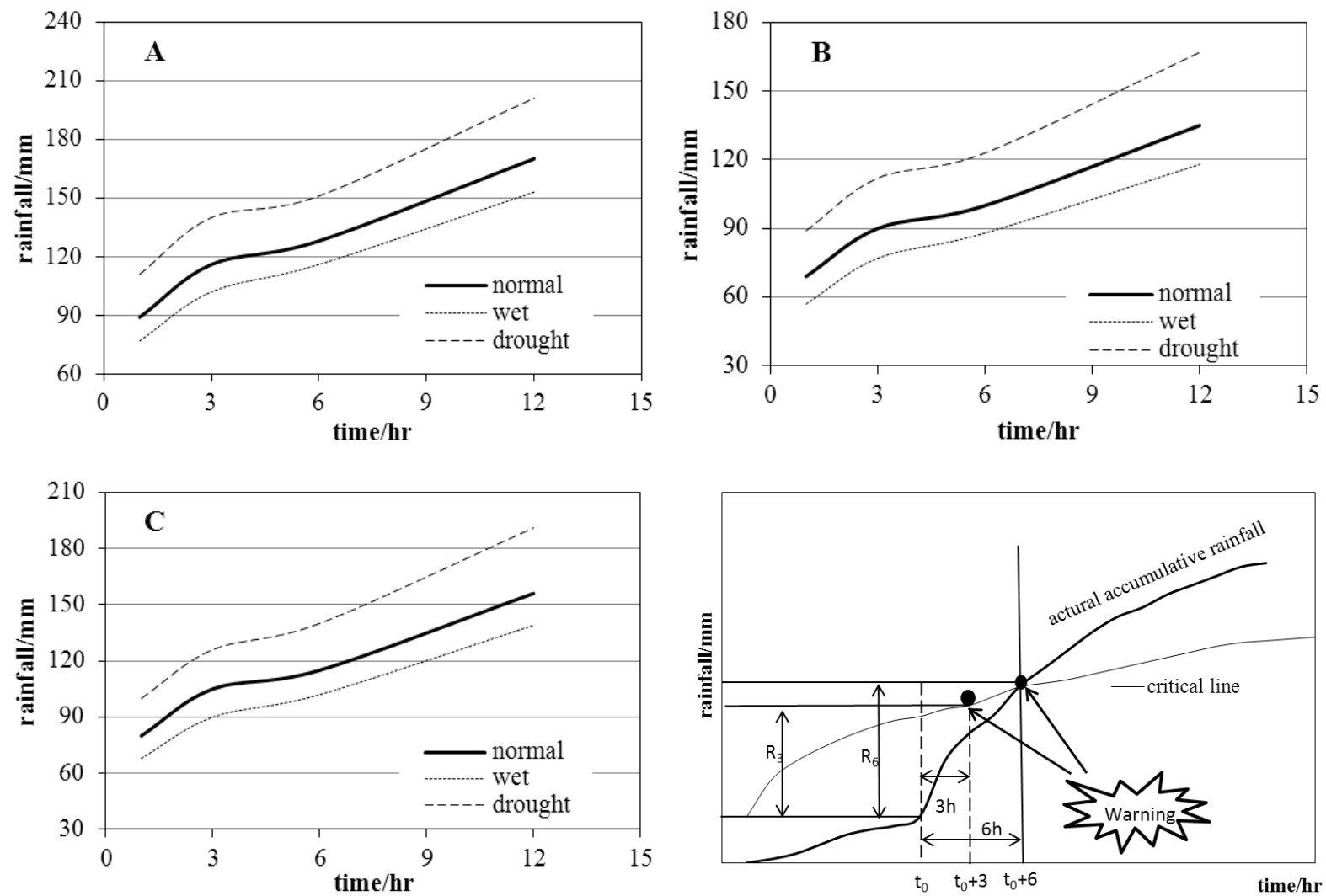

Fig. 6 Schematic application of critical rainfall at 3 warning stations.

\section{Conclusions}

This paper was initiated by summarizing critical rainfall analysis methods that are commonly used currently and reviewed flash flood forecasting and early warning progress in China. The research concept and approach using detailed hydrological model and manual for rainstorm-runoff computation to analyze critical rainfall depth were introduced. Taking the South Branch of Censhui watershed in Hunan province as an example, the method was illustrated by analyzing critical rainfall at 3 early warning stations of interest inside the watershed. The outcomes of this study are as follows:

(1) It is practical to analyze critical rainfall for flash flood early warning using hydrological model and manual for rainstorm-runoff computation. By delineating watershed into smaller sub-basins, the spatial variation of major watershed characteristics can be considered, and the rainstorm-runoff process and flood hydrograph at different locations can be better simulated. This research illustrates that detailed watershed characteristics in the context of several warning stations can be modeled in-depth by further delineating the watershed into smaller sub-basins to simulate spatial distribution of various basin parameters. The resulted flood runoff and flood hydrographs show considerable accuracy at all 3 early warning stations of interest within the watershed.

(2) In this method, the critical rainfall depth is obtained by reverse calculation using warning discharge threshold at each warning station, which is not a deterministic process, but a diverging process. Therefore, it is very important to determine accurately key factors to reduce the uncertainty during the analysis process, such as the warning discharge and warning rainfall duration for early warning stations, basin topography, land use and land cover, water course characteristics, and soil moisture content at watershed scale. In addition, the time of concentration 
of the watershed is important warning rainfall duration that can be regarded the longest warning rainfall duration for early warning, but typical durations shorter or longer than time of concentration should be reasonably considered for the sake of operability and safety in flash flood early warning.

(3) This study utilizes maximum storage capacity of the watershed and the antecedent soil moisture conditions to estimate soil moisture content in the watershed. The results confirm that soil moisture content at watershed scale has significant impact on critical rainfall estimation. Moreover, the critical rainfall depths increase as warning durations increase, regardless of the antecedent soil moisture condition.

While the proposed method in this study is promising for determination of critical rainfall for flash flood early warning in China in that most provinces have the key data for this method, there are also needs for improvements. Due to the complexity of the mountainous and hilly region, data collection and classification based on digital line data, remote sensing data and field investigation data need to be refined for distribution hydrological model. Soil moisture estimation method needs to be further enhanced other than only drought, common and wet scenarios. The parameter setting for runoff and flood routing process, as well as model calibration need in-depth study. In addition, although rainpatternplays an important role in rainstorm-runoff simulation, only design rain pattern in manual for rainstorm-runoff analysis was considered in this study, and rainfall series generation should also be improved with better accuracy. In order to provide dynamic flash flood early warning with better accuracy in China, detailed research should concentrate on real-time access or predication of rainfall information andsoil moisture content at watershed scale.

\section{Acknowledgements}

Thanks for finical support of project "National Flash Flood Hazard Prevention and Control (2013-2015)", and project "Theory and Method on Basin Level Flood and Drought Hazard Risk Management" (Jian No.0101092013).

\section{References}

[1] U.S. Department of Commerce, National Oceanic and Atmospheric Administration, National WeatherService. 1992. Modernized Areal Flash Flood Guidance. October.

[2] Carpenter, T. M. et al. 1999. "National Threshold Runoff Estimation Utilizing GIS in Support of Operational Flash Flood Warning Systems." Journal of Hydrology 224 (1-2): 21-44.

[3] FLOODsite. 2008. Realtime Guidance for Flash Flood Risk Management. March.

[4] Georgakakos, K. P. 1992. "Advances in Forecasting Flash Floods." In Proceedings of the CCNAA-AIT Joint Seminar on Prediction and Damage Mitigation of Meteorologically Induced Natural Disasters, 280-93.

[5] Sperfslage, J. A., Georgakakos, K. P., Carpenter, T. M., Shamir, E., Graham, N. E., Alfaro, R., and Soriano, L. 2004. Central America Flash Flood Guidance (CAFFG) User's Guide. HRC Limited Distribution Report No. 21. Hydrologic Research Center, San Diego, CA, 82.

[6] Sweeney, T. L. 1992. Modernized Areal Flash Flood Guidance. NOAA Technical Report NWS HYDRO 44, Hydrology Laboratory, National Weather Service, NOAA, Silver Spring, MD, 21.

[7] Georgakakos, K. P. 2006. "Analytical Results for Operational Flash Flood Guidance.” Journal of Hydrology 317 (1-2): 81-103.

[8] Gruntfest, E. 2001. "Beyond Flood Detection: Alternative Applications of Real-Time Data." NATO Science Series 77: 167-79.

[9] Brath, A. et al. 2001. "Estimating the Index Flood Using Indirect Methods." Hydrological Sciences Journal 46 (3): 399-418.

[10] Japan National Institute for Land and Infrastructure Management. 2001. Operating Methods of Critical Rainfall for Warning and Evacuation from Sediment-Related Disasters. No. 5 September.

[11] JAN, C. D., LEE, M. H., WANG, J. S., and WANG, C. L. 2004. “A Rainfall-Based Debris-Flow Warning Model and Its Application in Taiwan.” International Conference on Slope Disaster Mitigation Strategy, Taipei, 111-9.

[12] JAN, C. D., LEE, M. X., and GUO, F. H. 2006. "Rainfall Warning Mode for Spatial and Temporal Characteristics of Debris Flow." Geotechnical Technology 110 (3): 55-64. (In Chinese)

[13] CHEN, G. Y., and YUAN, Y. M. 2005. "Research on Critical Precipitation Amount Computation Method of Mountain Torrential Flood Disaster." YangtzeRiver 36 (12): 40-3. (In Chinese) 
[14] YE, Y., WANF, Z. Y., and FAN, B. Q. 2008. "Flash Flood Critical Rainfall Estimation for Small Watershed in Jiangxi Province."Journal of Hydrology 28 (1): 56-8.

[15] JIANG, J. H., and SHAO, L. P. 2010. "Standard of Mountain Flood Warning Based on the Precipitation Observation Data." Journal of Hydraulics 41 (4): 458-63. (In Chinese)

[16] WANG, X., CAO, Z. X., and TAN, G. M. 2009. "Shallow
Water Hydrodynamic Modelling of Rainfall Induced Flash Flooding." Engineering Journal of Wuhan University 42 (4): 413-6. (In Chinese)

[17] Hunan Provincial Department of Water Resources and Hydropower. 1984. Manual for Rainstorm-Runoff Analysis in Hunan Province. (In Chinese)

[18] CHEN, J. Q., and ZHANG, G. S. 1984. Rainstorm-runoff Computation for Small Watershed. Water Resources and Hydropower Press. (In Chinese) 